\title{
Implications of Implementation of Artificial Intelligence in the Banking Business with Correlation to the Human Factor
}

\author{
Krunoslav Ris ${ }^{1}$, Zeljko Stankovic ${ }^{2}$, Zoran Avramovic ${ }^{2}$ \\ ${ }^{1}$ Information Systems in Communication and Logistic, Pan-European University APEIRON, Banja Luka, Republic of Srpska, \\ Bosnia and Herzegovina \\ ${ }^{2}$ Pan-European University Apeiron, Banja Luka, Republic of Srpska, Bosnia and Herzegovina \\ Email: krunoslav.ris@gmail.com,stanz@medianis.net,zoran.z.avramovic@apeiron-edu.eu
}

How to cite this paper: Ris, K., Stankovic, Z. and Avramovic, Z. (2020) Implications of Implementation of Artificial Intelligence in the Banking Business with Correlation to the Human Factor. Journal of Computer and Communications, 8, 130-144. https://doi.org/10.4236/jcc.2020.811010

Received: October 22, 2020

Accepted: November 24, 2020

Published: November 27, 2020

Copyright $\odot 2020$ by author(s) and Scientific Research Publishing Inc. This work is licensed under the Creative Commons Attribution International License (CC BY 4.0).

http://creativecommons.org/licenses/by/4.0/ (c) (i) Open Access

\begin{abstract}
Banks daily interact with a vast number of customers and are still depending on a legacy system. With today's advances in technology, regarding lifting almost all processes to automation, from start of production to finish, there is a need for revolution in archaic monetary management institutes. By not being in tune with the contemporary trends and times, banks are losing on an opportunity to transform some of their business models and relieve humans of repetitive work, prevent frauds, make better decisions and consequently gain losses. Banks can engage in implementation of new Virtual Assistants and Artificial Intelligence (A.I.) machine learning technologies, just as the other industries have engaged in modernizing i.e. medical checks, medical reports and evaluations, and this research paper will elaborate and emphasize the impact of artificial intelligence implementation on the banking sector processes. This research is based on both quantitative and model-based proofs of system performance by using several analytical tools, such as SPSS. The automation process helps institutions to enhance profitability, performance and to reduce human dependency. In a nutshell, Virtual Assistants powered with Artificial Intelligence improve the business process performance in every sector of business, especially the banking sector making it fast, reliable and not human dependent.
\end{abstract}

\section{Keywords}

Artificial Intelligence, Machine Learning, Automation, Banking Systems, Virtual Assistants, Chatbots 


\section{Introduction}

Rules and regulations are the foundation of banking sector. Artificial intelligence is used to spare time that would take a human to process information that is high in volume and it provides results that are lower in cost and more accurate.

The information technology implementation in the banking sector has become a global trend and is adopted by every country. The application of technology not only supports business automation; it also increases the number of customers and finance remittance by decreasing the banking cost [1]. The banking sector is transforming the entire system into the technology system. A large number of customers in the banking sector mean adapting the innovative methods of technologies in the banking sector. There is a significant increase in the customer in the middle east from $20 \%$ to $25 \%$ by adjusting the mobile technology in the banking sector [2].

The UK (United Kingdom) banking sector is the role model for the implementation of new technological inventions banks likes "NBD (National Bank of Development)", and "Islamic Banka" that is considered as a leader to implement the digital services in the bank [3].

The research paper based on the "Digitalization in Consumer Banking" is written about the infrastructure of the banking system after ten years. Darryl Proctor writes this research paper in the year 2019. According to this research paper, the banking sector, after ten years, will be more advanced and totally will be based on machine learning algorithms; even for the processing of payments will be digitized in such a way that the paper currency concept will be abolished. Their findings are significant with their research question. According to this research, the person only needs to be an account in the personal bank. The blockchain technology will be implemented. The human needs will be met at the doorstep. The results from this research clearly describe the positive impact of technology over the banking sector in the next ten years. All the documentation will be done using the A.I. and Machine learning algorithms [4].

Artificial intelligence is implemented in banking system through algorithms with great success in custom management services, Credit Information Service, Frequently Asked Questions (FAQ) service, Financial Assistance Service, etc.

Nowadays, the enhancement in performance of a banking system is done by applying the A.I. in various fields such as cybersecurity, risk management, fraud management, sales, Internal Audit, Financial Assistance, Asset Management, Loan Management, and Customer Management [5].

This research paper will elaborate on the framework of an A.I. system that will be implemented in all fields of banking sectors that has been discussed earlier. These models will be pre-tested using historical data and survey forms. These models can be applied in any or all fields of the banking sector to automate the business process using a robot-processing, Chatbot, and A.I. agent.

To enhance the customer services, the customer doesn't need to visit a bank physically, he just needs to visit the website, and the pre-defined Chatbot starts 
scraping the required data. When the primary data is gathered, Chatbot starts questioning about the problems to check if meets the edibility criteria and to know should it continue to communicate or to stop communication. If the problem statement is covered with the Chatbot algorithm, then the Chatbot will proceed and guide the customer according to the written instructions. But in another case, the Chatbot will guide the customer to visit the nearby branch physically to get the problem solved.

A Chatbot's advantage is that it will collect the information from data warehouse much faster than a human ever could, which results in much better performance. Performance is another critical aspect of the data warehouse as it is based on proper structure and great query engines that are fully optimized for reading and are supporting various incremental changes in the data. Another important characteristic is usability as users may not be familiar with how to get information from source data, but with the analytical approach of the data warehouse, users can by transforming, filtering, or slicing the data to find the information they need. In this way, users are getting a single source of data, which will be processed by A.I. instead of matching various sources of data, trying to find the information they are looking for [6].

An A.I. system monitors transactions and traffic in an organization to prevent a fraud. System records the logs and in case of a blacklisted transaction being processed multiple times by an employee and A.I. notices the fraud. The system works intelligently and does not interrupt transactions and also learns by experience [7].

Finding information using computational methods gives immeasurably better results compared to data retrieval that relies only on classical methods [8].

For operation efficiency improvement the front-end system is integrated with the A.I. system in which user is required to input only the single field information and the intelligent learning populates the rest if the required fields. All data is filled in the rest of the fields automatically, the insight and analysis are provided very fast and an immediate decision can be made. A.I. makes process of tracing documents in real-time comfortable and efficient [9].

The commercial banks are moving to cutting edge technologies and process automation. Unicredit Bank has launched its Emerging Opportunities Engine (EOE) that is used to predict the investment recommendation and primarily focuses on the capital market. It also guides the customer to purchase the shares or sales in the stock market, and it is beneficial for the trading brokers. The initial results of this software are good, so the software is going to implement in the financial institutes [10] [11].

The artificial intelligence adaption can help bank and finance industry make consistent and faster engagement of customers to their business by following the quick address of their problems. A.I. base software uses Machine Learning Algorithms that help the system to understand the procedure of problem and solve it according to the algorithm set of instructions [12].

Only tool that can carry out the urgent need for converting data into useful 
information and knowledge in a rapid manner to meet customer requirements is artificial intelligence powered with machine learning algorithms [13] [14].

This research paper has proven that clients will adapt to technologies, even the ones they have had initial resistance to. This was also proven during the Covid-19 crisis in 2020. According to this research, financial and other institutions could be sure that digital transformation, robotics and 24-hour availability through Virtual Assistants and Chatbots are long-term profitable investments.

\section{Problem Statement}

The problem with the existing and outdated banking system is to make a decision based on massive data, it is very expensive in term of cost as well as about twenty to thirty percent made decisions goes wrong due to incomplete and inappropriate information on the organizational plan. The A.I. state of the art system will deal with these issues intelligently and monitor all the information related to stakeholders to process the reports. This A.I. system will use real-time data to coordinate and guide the customer to take immediate decisions and govern according to the rules and regulations. This system will also maintain the profitability of the organization by increasing the credit by conducting multiple customers at the same time on the right way to immediately invest the money in the banking sector.

\subsection{Hypothesis}

Information systems of financial institutions with a strong artificial intelligence are an autonomous set of individual subsystems of all stakeholders of a financial organization, which must cognitively/logically make the relevant decision regarding a particular procedure based on the investigated parameters at the macro and microeconomic level. The system should achieve interoperability of all components in order to function smoothly and safely [15].

Interoperability at the organizational, logical, research and technological level creates essential technical and human preconditions for achieving full system interoperability as ideal. The assumption is that the system may be so ideal that it can completely replace the human factor through defined safety limits by manually checking individual procedures when resolving financial procedures.

The use of controls of organizational, financial and technological interoperability through the regular security procedures of the information system ensures a smooth, fast, accessible and secure operation of the information system in the domain of financial institutions.

Such hypotheses will be tested by research to be conducted in a leading bank in the Central and Eastern European (CEE) market, based on the example of the Informatics Division.

\subsection{Objectives of the Research}

The purpose of this research is to highlight the need and opportunities to im- 
prove the efficiency, effectiveness of service delivery and increase the profits of financial institutions and replace human factors with automatic Virtual Assistants and Chatbots. Full automation electronic services are the future of the functioning of all systems within financial organizations. On the other hand, the research goals are oriented towards the improvement of the model of information systems audit in public administration and its specific business.

One goal is to show how financial institutions with widespread machine learning models (which replicate human intuition and intelligence) provide digital platforms (information systems) with a way to reduce costs, reduce the workforce, improve banking experience and maximize profits.

The second objective of the research is to further improve the existing information system modules in order for the results to be realistic and, in scientific postulates, a finding that will improve the system and improve the degree of customer service provision.

The third objective of the research is to make a scientific and professional contribution to the development of artificial intelligence within financial institutions. This will be achieved by the aforementioned enhancement of the model that is currently generally and widely applicable.

The fourth objective of the research is to contribute to improving the quality of service delivery of financial institutions at all levels, since the model ensures system interoperability.

The offered extension and improvement do not refer to the steps in the internal processes of financial institutions, that is, does not create a completely new model of internal processes that has some special or special steps, but rather this improvement relates to its essence, subject and scope. In other words, the model offered will follow existing practices and contribute to expanding the scope of issues that test system interoperability and the effects of interoperability implementation in line with other entity functionalities, and in particular, the security of the system itself.

The offered model will be specific for financial institutions, but it will be possible to apply it to other types of organizations (agencies, credit unions, credit rating companies). The issue of semantic interoperability is a challenge that is central to new and emerging technologies (especially when it comes to the "Internet of Things" paradigm) but also to ensuring "intelligibility" between different systems. It is a universal paradigm, and therefore can be applied to different systems, thus creating an environment in which the system will function and communicate in an understandable "language".

Research has confirmed that people would rather use virtual assistants and Chatbots rather than go to a bank branch.

\subsection{Research}

In the modern era of technology, automation and utilization of technology in the field of banking has increased. Because the world is moving to the Global Village 
concept in which anyone from anywhere can get its desired product without lifting the boxes of cash in hand. The banking sector nowadays has been completely transferred to the technology; due to this, it would make it possible to purchase any product from anywhere in the world. Several algorithms are working behind the technology to process the information and customer request on all types of banking services like online banking, android apps banking, digital banking, ATM transfer, Wire transfer, etc. All these types of services have been synchronized with the banks using machine learning algorithms that automatically track data, verify the integrity of data, and synchronize it with the central database of the concerned bank. For all demands that are mentioned, there is a need to utilize workforce which needs to be available 24/7. Availability of man powers $24 \mathrm{~h}$ in a day increases banks' operational costs and decreases profit. The purpose of the research is to find out will customers accept to use robots, Virtual Assistants and Chatbots instead of real human beings.

\subsection{Algorithms}

Several algorithms can be used for data mining in Machine learning, but some of those are only used within the banking sector. There are two main types of machine learning data mining algorithms that we are using in building new A.I. Framework.

1) Supervised Learning Algorithms

2) Unsupervised Learning Algorithms

\subsection{Datasets}

Dataset consists of 517 observations that are obtained from the survey. The survey was taken on the tablet computers that were placed in the three bank branches' offices. One office in Unicredit Milan, Italy, one in a local branch office of Zagrebačka Banka, which is part of Unicredit Group in Osijek, Croatia, and one in Zagreb, Croatia. The tablets were placed in three locations because only private tablet devices could be used for the purpose of the research. Bank rules forbid installing of any third-party programs and internet access to the bank computers inside branch offices for security reasons. The survey was conducted from the $1^{\text {st }}$ of October 2019 until the $21^{\text {st }}$ of October 2019. In this period, 517 people answered all questions. This dataset consists of 37 different questions from the personal info to business info. Some of the questions in the survey were:

1) Have you ever chatted with a Chatbot?

2) Has your bank had offered Chatbot functionality/support?

3) Do you prefer using Chatbots in a Banking Business?

4) If you can do most of your Banking Business through Chatbot, would you still go to the Bank branch office?

5) Would you like to talk to your Bank virtual assistant like you are chatting with a Chatbot? 
As being the research topic, these questions are most important in the statistical analysis. This hypothesis testing will be done using the IBM SPSS V.23 statistical analysis tool. SPSS is an abbreviation of Statistical Package for the Social Science that has many versatile and automated analysis algorithms for both the qualitative and quantitative analysis. There are many features of SPSS, such as it can handle a large amount of data and manipulate the human-understandable logical results according to the applied algorithm. It used elementary statistics function as well as advanced features to measure the output. The most appropriate models like ANOVA, Correlation, Means, Chie Square Test, and multiple regression test, can be implemented in SPSS.

\section{Methods and Techniques}

Two models are designed to this dataset in order to analyze the validity of the dataset as well as the hypothesis. For the validity of the dataset, the frequencies algorithm is applied to validate the ratio of each attribute. Later on, the Multinomial Logistic Regression is applied to understand the validity of the hypothesis statement; either the hypothesis is accepted or rejected.

\subsection{Frequencies Analysis}

\subsubsection{What Is Your Age Group}

In Table 1, there are 6 different age groups and according to the table 194 surveyed candidates are 35 - 44 years old, while the second biggest group consists of 164 candidates ages between 25 - 34. The second column in Table 1 shows the frequency of how many participants belong in which age group. The percent column displays the percentage of overall data, while the valid percentage column shows the data validity percentage of total dataset. The total valid percentage dataset is $100 \%$.

\subsubsection{What Is the Gender Distribution}

Gender study is important in any survey showing the technological aspect of life.

It is important to analyze the impact of technology on each gender, as it is shown in Figure 1 61.4\% survey candidates were male, 38\% female and $0.6 \%$ decided not to disclose gender.

Table 1. Frequency table what is your age group?

\begin{tabular}{cccccc}
\hline & Frequency & Percent & Valid Percent & Cumulative Percent \\
\hline \multirow{4}{*}{ 18 - 24 years old } & 53 & 10.1 & 10.1 & 10.1 \\
& $25-34$ years old & 164 & 31.7 & 31.7 & 41.8 \\
& $35-44$ years old & 194 & 37.5 & 37.5 & 79.3 \\
& $45-54$ years old & 80 & 15.5 & 15.5 & 95.0 \\
& $55-64$ years old & 19 & 3.7 & 3.7 & 98.6 \\
& $65-74$ years old & 7 & 1.4 & 1.4 & 100.0 \\
Total & 517 & 100.0 & 100.0 & \\
\hline
\end{tabular}




\subsubsection{Have You Ever Chatted with a Chatbot}

The status of chat over Chatbot is discussed in Table 2. Most candidates use Chatbots for the purpose of answering frequently asked questions. The second column in Table 2 shows frequency of how many participants belong in which group. The percent column displays the percentage of overall data, while the valid percentage column shows the data validity percentage of the total dataset. The total valid percentage dataset set is $100 \%$.

\subsubsection{Chatbot Communication Experience Rate}

Figure 2 shows how have candidates rated their experience with Chatbot. Three most often grades are 5 ( 75 candidates), 6 (57 candidates) and 7 (66 candidates).

\subsubsection{Does Your Bank Offer Chatbot Functionality/Support}

In Table 3, the total value is 517, out of which the majority belong to answer No. That means the results are not favorable in Table 3. The second column shows the frequency of how many participants belong in a certain group. The percent column displays the percentage of overall data, while the valid percentage column shows the data validity percentage of the total dataset. The total valid percentage dataset set is $100 \%$.

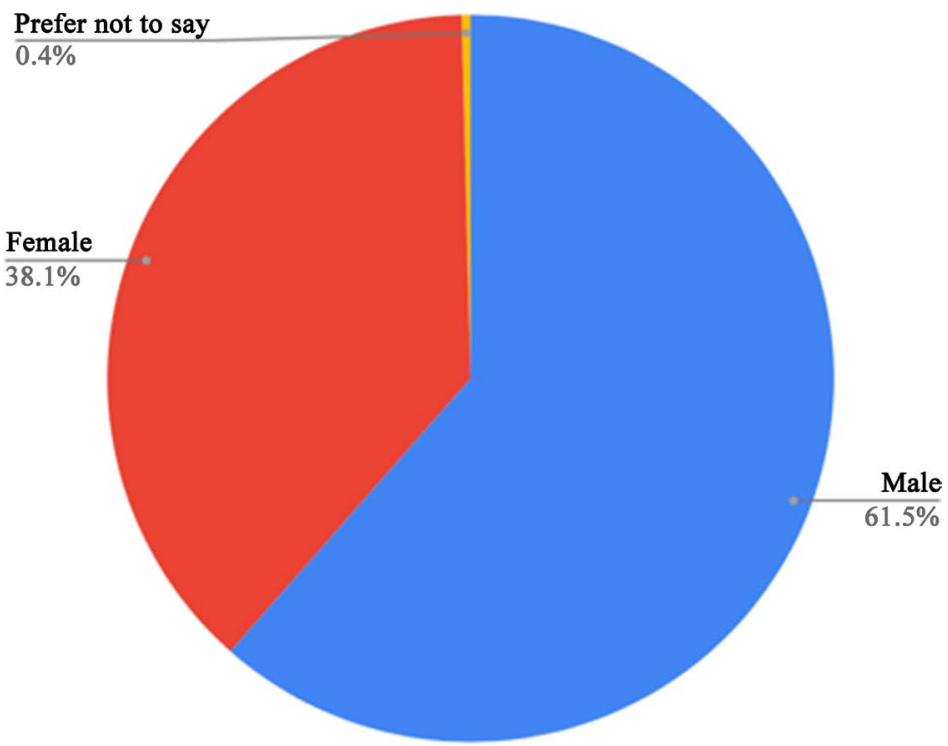

Figure 1. Frequency graph what is your gender?

Table 2. Frequency: have you ever chatted with a Chatbot?

\begin{tabular}{ccccc}
\hline & Frequency & Percent & Valid Percent & Cumulative Percent \\
\hline Not Answered & 1 & 0.2 & 0.2 & 0.4 \\
Maybe & 1 & 0.2 & 0.2 & 0.4 \\
No & 195 & 37.7 & 37.7 & 38.1 \\
Prefer not to say & 10 & 1.9 & 1.9 & 40.0 \\
Yes & 310 & 60.0 & 60.0 & 100.0 \\
Total & 517 & 100.0 & 100.0 &
\end{tabular}




\subsubsection{Do You Prefer Using Chatbots in a Banking Business}

In Figure 3, the total values are 517, out of which the majority belong to negative answer. That as well means the results are not favorable. The second column is showing the frequency of how many participants there are in a certain group. The percent column displays the percentage of overall data, while the valid percentage column shows the data validity percentage of the total dataset. The total valid percentage dataset set is $100 \%$.

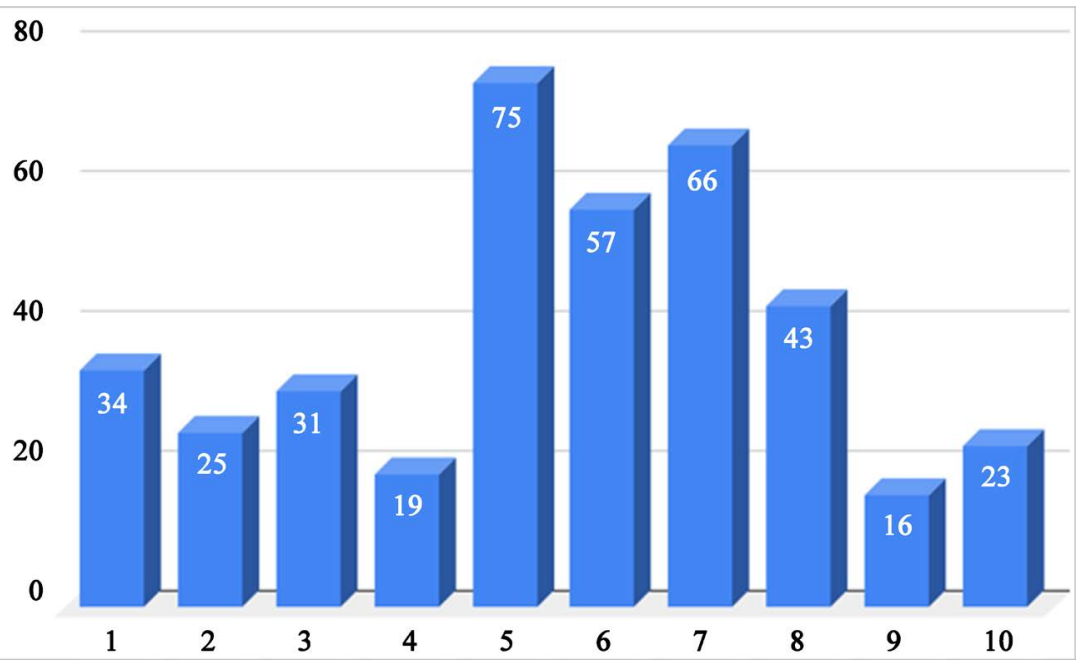

Figure 2. Rate your experience with Chatbots.

Table 3. Frequency: does your bank offer Chatbot functionality/support?

\begin{tabular}{cccccc}
\hline & & Frequency & Percent & Valid Percent & Cumulative Percent \\
\hline \multirow{2}{*}{ I don't know } & 148 & 28.6 & 28.6 & 28.6 \\
& No & 212 & 41.0 & 41.0 & 69.6 \\
& Yes & 1 & 0.2 & 0.2 & 69.8 \\
& Yes & 156 & 30.2 & 30.2 & 100.0 \\
& Total & 517 & 100.0 & 100.0 &
\end{tabular}

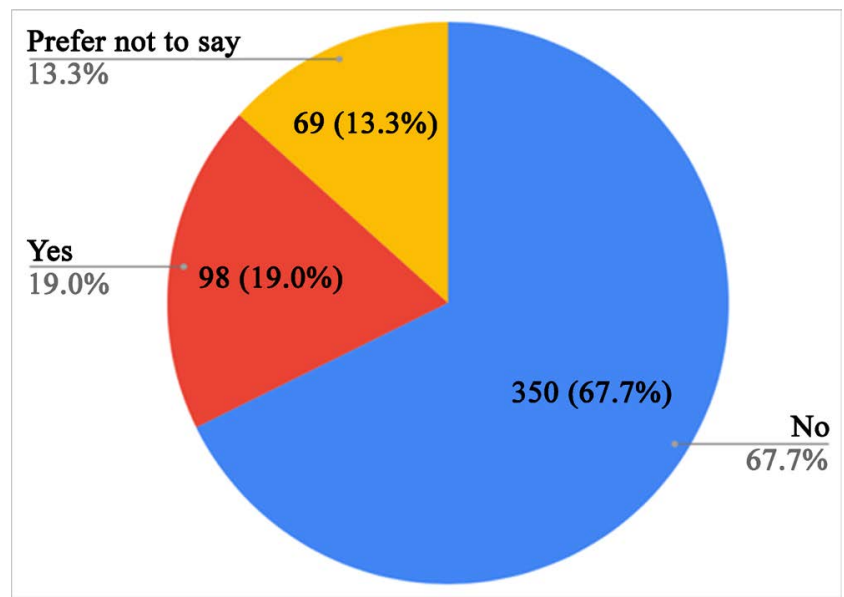

Figure 3. Do you prefer using Chatbots in Banking Business? 


\subsubsection{Banking Business with Chatbots or Going to a Branch Office}

In Figure 4, most of the responses suit the Chatbot in which the user prefers to use Chatbot instead of visiting the branch, as about 299 are disagreeing with visiting branch, but they prefer to use Chatbot for the problem solution. The second column is showing the frequency of how many participants belong in a certain group. The percent column displays the percentage of overall data, while the valid percentage column shows the data validity percentage of the total dataset. The total valid percentage dataset set is $100 \%$.

\subsubsection{If You Could Talk to a VA Anytime, Would You Still Prefer Going to a Branch Office}

In Table 4 it is shown that most of the candidates want to use Chatbot to talk to as a virtual assistant and get prompt responses instead of waiting for a long time. The second column is showing the frequency of how many participants belong to a certain group. The percent column displays the percentage of overall data, while the valid percentage column shows the data validity percentage of the total dataset. The total valid percentage dataset set is $100 \%$.

\subsection{Multinomial Logistic Regression}

Multinomial Logistic Regression is used to predict a nominal dependent variable given one or more independent variables. It is used to predict the nominal

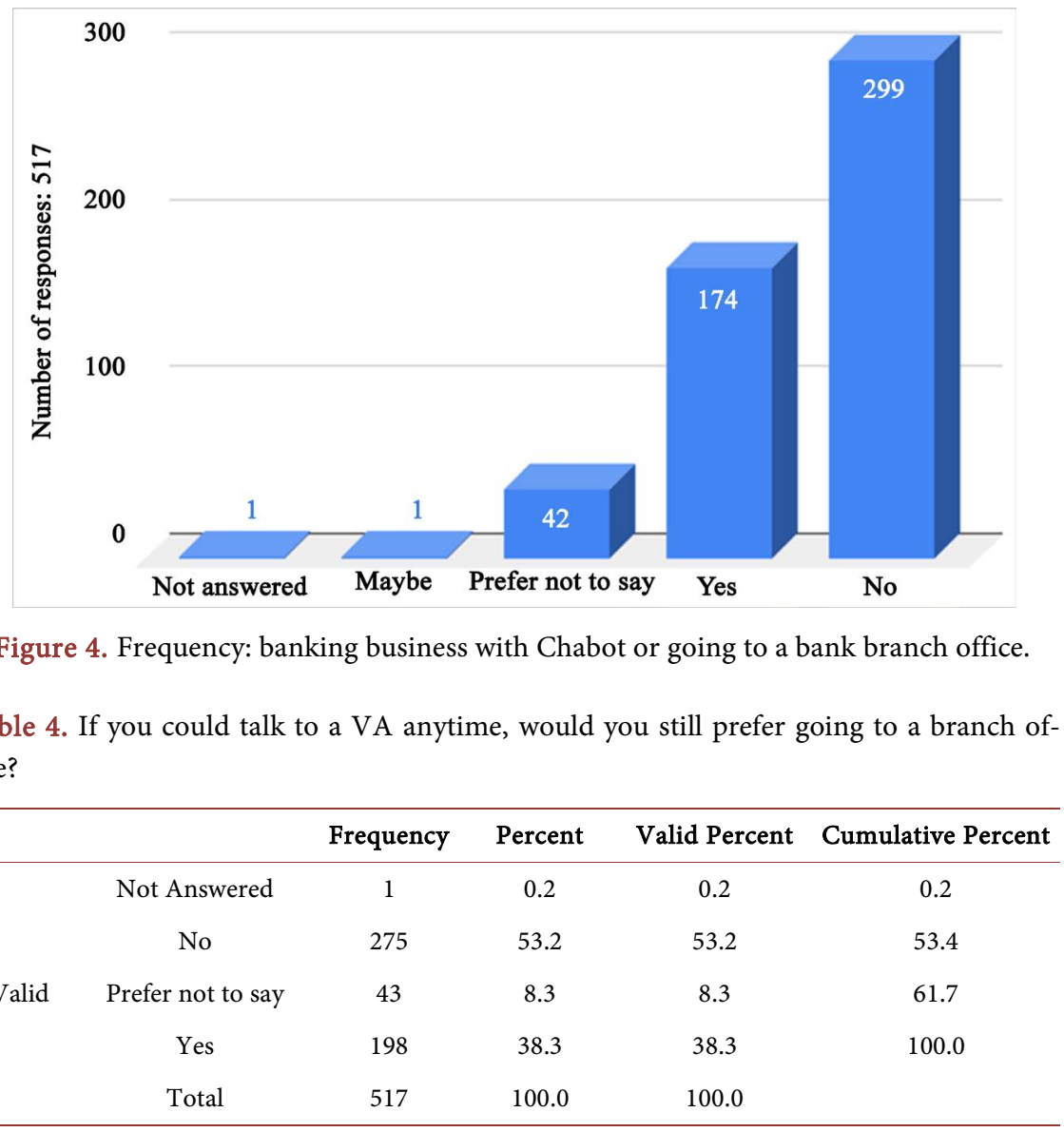


variables. As the dataset consists of the many string values, so the best model that fits for the analysis of dataset validity is multinomial

Logistic Regression.

For model validity, two variables are selected for this test:

1) Sex

2) Do you prefer using Chatbot in a Banking Business?

The first variable is used as an independent variable, and the second is used for the dependent variable. The results of the test are shown in Table 5.

In Table 5, column $\mathrm{N}$ provides the number of observations used in the model. There are three possible answers: male, female, and prefer not to say. The next column, Marginal Percentage, is providing the list of valid observation funds in each outcome variable. The validity is calculated by dividing the total observation with the number of views per category. In Table 5, the valid means how much data or views are valid from the total observations. The dataset validity rate is $100 \%$. The following result shows the number of subpopulations included in the data. A subpopulation of the input data consists of an individual sequence of the predictor variables set for the model.

In Table 6, the first column is a model that contains two parameters: The Intercept Only and Final. This means the parameters of the model for which the model fit is calculated. "Intercept Only" represents a model that does not control for any predictor variables and fits an intercept to predict the result variable.

Table 5. Summary result table Multinominal Logistic Regression of independent Variable "Do you prefer using Chat Bots in a banking Business".

\begin{tabular}{cccc}
\hline & & N & Marginal Percentage \\
\hline $\begin{array}{c}\text { Do you prefer using Chatbots } \\
\text { in a Banking Business }\end{array}$ & No & 351 & $67.8 \%$ \\
Sex & Prefer not to say & 69 & $13.3 \%$ \\
& Yes & 98 & $18.9 \%$ \\
& Female & 197 & $38.0 \%$ \\
Male & 318 & $61.4 \%$ \\
Missing & Prefer not to say & 3 & $0.6 \%$ \\
Total & & 518 & $100.0 \%$ \\
Subpopulation & 0 &
\end{tabular}

Table 6. Model Fitting information representation of independent variable.

\begin{tabular}{ccccc}
\hline \multirow{2}{*}{ Model } & Model Fitting Criteria & \multicolumn{3}{c}{ Likelihood Ratio Tests } \\
\cline { 2 - 5 } & -2 Log Likelihood & Chi-Square & df & Sig. \\
\hline Intercept Only & 41.760 & 20.461 & 4 & 0.000 \\
Final & 21.299 & & & \\
\hline
\end{tabular}


"Final" defines a model that includes the particular predictor variables and has been obtained through an iterative method that increases the log-likelihood of the results seen in the result variable. By adding the predictor variables and maximizing the log-likelihood of the results seen in the data, the "Final" model should develop upon the "Intercept Only" model. This can be seen in the variations in the -2 (Log-Likelihood) values correlated with the models.

The second column is about the model fitting criteria by which the model outcomes are produced. This is the result of -2 and the log-likelihoods of the null model and provided "final" model. The likelihood of the model is tested whether all predictors' regression coefficients in the model are concurrently zero and in tests of nested models.

Chi-Square-This is the Likelihood Ratio (L. R.) Chi-Square test that minimum one of the predictors' regression coefficient isn't equal to zero in the model. The L. R.

Chi-Square statistic is calculated by

$$
-2 * L_{\text {null model }}-\left(-2 * L_{\text {fitted model }}\right)=41.760-21.299=20.299
$$

wherever $L$ (null model) is from the log-likelihood including just the response variable in the model (Intercept Only) and $L$ (fitted model) is the log-likelihood from the final repetition (assuming the model converged) by all the parameters.

$\mathrm{df}$-indicates the levels of freedom of the chi-square distribution used to examine the L. R. Chi-Square statistic and is defined by the number of predictors in the model.

Sig.-This is the probability of getting a Multinomial Regression test statistic being as extreme as, or more so, than the observed statistic under the null hypothesis. This model indicates the $\mathrm{p}$-value. The $\mathrm{p}$-value is used to determine the model authentication and hypothesis; either the hypothesis is accepted or not, and the results are significant or not. The standard value of $p$ should be $p$-value $\leq 0.05$ for the significance of the model. In this case, the sig value is lower than 0.05 that indicates the null hypothesis is rejected, and results are significant.

In Table 7, the second column indicates the relationship between the dependent and independent variables. These are the estimated multinomial logistic regression coefficients for the models. An important feature of the multinomial logit model is that it estimates $k-1$ models, where $\mathrm{k}$ is the number of levels of the outcome variable. At the bottom of this table at point, a indicates that the YES is used as a reference category that is significant with the results. The standard error of the individual regression coefficients for the two respective models estimated. In the next column, Wald chi-square test that tests the null hypothesis that the estimated equals. While the $\mathrm{df}$ is the list of columns that have the degree of freedom of each variable in the dataset. The degree of freedom is used in this dataset is 1 .

The most important column in this table is sig that is also known as the p-value table. It is the coefficient of the probability that is given in the model. For the best fit and result from the model, sig value should be sig $\leq 0.05$, which is 
Table 7. Survey question: "Do you prefer using Chat Bots in a Banking Business" parameter estimation.

\begin{tabular}{|c|c|c|c|c|c|c|c|c|c|}
\hline \multicolumn{10}{|c|}{ Parameter estimates } \\
\hline \multirow{2}{*}{\multicolumn{2}{|c|}{$\begin{array}{l}\text { Do you prefer using Chatbots in } \\
\text { a Banking Business? The } \\
\text { reference category is: Yes. }\end{array}$}} & \multirow{2}{*}{ B } & \multirow{2}{*}{$\begin{array}{l}\text { Std. } \\
\text { Error }\end{array}$} & \multirow{2}{*}{ Wald } & \multirow{2}{*}{ df } & \multirow{2}{*}{ Sig. } & \multirow{2}{*}{$\operatorname{Exp}(B)$} & \multicolumn{2}{|c|}{$\begin{array}{l}\text { 95\% Confidence } \\
\text { Interval for } \operatorname{Exp}(\mathrm{B})\end{array}$} \\
\hline & & & & & & & & Lower & Upper Bound \\
\hline \multirow[t]{5}{*}{ No } & Intercept & 15.916 & 0.146 & $11,916.015$ & 1 & 0.000 & . & . & . \\
\hline & Sex $=$ Female & -14.826 & 0.236 & 3959.175 & 1 & 0.000 & $3.639 \mathrm{E}-7$ & $2.293 \mathrm{E}-7$ & $5.776 \mathrm{E}-7$ \\
\hline & Sex $=$ Male & -14.547 & 0.000 & . & 1 & & $4.811 \mathrm{E}-7$ & $4.811 \mathrm{E}-7$ & $4.811 \mathrm{E}-7$ \\
\hline & Sex $=$ Prefer not to & 0 & . & . & 0 & . & . & . & . \\
\hline & say & $\begin{array}{l}\text { This parameter is set } \\
\text { to zero because it is } \\
\text { redundant. }\end{array}$ & & & & & & & \\
\hline \multirow{5}{*}{$\begin{array}{c}\text { Prefer } \\
\text { not to say }\end{array}$} & Intercept & -0.351 & 1967.015 & 0.000 & 1 & 1.000 & . & . & . \\
\hline & Sex $=$ Female & 0.425 & 1967.015 & 0.000 & 1 & 1.000 & 1.530 & 0.000 & Floating point overflow \\
\hline & Sex $=$ Male & -0.431 & 1967.015 & 0.000 & 1 & 1.000 & .650 & 0.000 & $\begin{array}{l}\text { occurred while } \\
\text { computing this statistic. } \\
\text { Its value is therefore set } \\
\text { to system missing. }\end{array}$ \\
\hline & Sex $=$ Prefer not to & 0 & . & . & 0 & . & . & . & . \\
\hline & say & $\begin{array}{l}\text { This parameter is set } \\
\text { to zero because it is } \\
\text { redundant. }\end{array}$ & & & & & & & \\
\hline
\end{tabular}

given in the table. According to this, it is concluded that the model is significant and the null hypothesis is rejected.

\section{Conclusions}

Today substantial financial resources are being invested in reducing the company's operating expenses and increasing productivity. That is where artificial intelligence rises as the best choice; it is faster, more reliable and has a lesser chance for mistake than a human. Virtual assistants, Chatbots, holograms, physical robots will upgrade over the years to flood the market due to all the cheap technologies. Man as an individual will become conceptually obsolete and will not be able to fulfill the need for processing a large amount of necessary daily information. Each of us will need a personal assistant who will take care of things for us, from arranging a meeting, reminders, providing information, all the way to a mentor or educator for a particular area of interest. Hard, repetitive and manual labor will be replaced for the benefit of humans.

An army of people who, about ten years ago processed data in the FinTech industry and needed to crawl that data from databases, will be engaged with other creative jobs.

Today it is no longer essential to have bank offices in a small community. Today, it is only important that this small community has an Internet connection, and spare time that will be utilized as they want. 
The hypothesis of this research paper was proven by result interpretation. Used statistical models are ANOVA, T-Test, and the latest possibilities of SPSS tools such as multinomial regression tests and regular regression tests.

A survey of 517 respondents was proven, resulting in the majority of users who worked sitting at home and setting up their virtual existence to do the work for them. The future is already today. The days of going to commercial banks and wasting time waiting for someone behind the counter to shout "Next" are gone.

\section{Conflicts of Interest}

The authors declare no conflicts of interest regarding the publication of this paper.

\section{References}

[1] Waston, S. (2018) Banks Are Investing Massively into IT Services. https://www.forbesmiddleeast.com/featured/special-editions/banks-are-taking-note -as-fintech-spikes-customers-interest

[2] John (2018) How Technology Will Change the Banking. https://www.khaleejtimes.com/business/banking-finance/how-technology-will-chan ge-the-banking-industry

[3] Twin, M. (2018) Digital Banking in the USA Keeping Pace with Consumers in Fast Moving Market Place.

https://www.mckinsey.com/ /media/mckinsey/locations/europe\%20and\%20middle \%20east/middle\%20east/overview/insights/digital\%20banking\%20in\%20the\%20gulf /digital\%20banking\%20in\%20the\%20gulf\%20161116\%20digital.ashx

[4] Porkelsson, S. (2017) Digitalisation in Consumer Banking. 96.

[5] Parsons, G., et al. (1993) Productivity and Computers in Canadian Banking. Journal of Productivity Analysis, 4, 95-113.

https://econpapers.repec.org/article/kapjproda/v_3a4_3ay_3a1993_3ai_3a1_3ap_3a 95-113.htm

[6] Šikanjić, N. and Avramović, Ž.Z. (2019) New Approach of Storing and Retrieving Large Data Volumes. Journal of Information Technology and Applications, 9, 89-98.

[7] Sloane, T. (2018) The 18 Top Use Cases of Artificial Intelligence in Banks. https://www.paymentsjournal.com/the-18-top-use-cases-of-artificial-intelligence-in -banks

[8] Avramović, Ž., Marinković, D. and Lastrić, I. (2017) Use of Computer Search Algorithms in the Research of Statistical, Semantic and Contextual Rules of Language in Digital Information Space. Journal of Information Technology and Applications Banja Luka, 7, 5-8. https://doi.org/10.7251/JIT1701005A

[9] Schank, R. (2016) Once upon a Time in AI. Artificial Intelligence, 170, 1254-1255. https://doi.org/10.1016/j.artint.2006.10.010

[10] HINA, UniCredit predstavlja strateški plan, 2019. https://www.glasistre.hr/gospodarstvo/unicredit-predstavio-strateski-plan-ukida-80 00-radnih-mjesta-do-2023-608293

[11] Pavlou, P.A., Lie, T. and Dimoka, A. (2007) What Drives Mobile Commerce? An 
Antecedent Model of Mobile Commerce Adoption. https://doi.org/10.2139/ssrn.2380712

[12] Rostami, N.A. (2014) Integration of Business Intelligence and Knowledge Management-A Literature Review. Iran Journal of Intelligence Studies in Business, 4, 30-40. https://doi.org/10.37380/jisib.v4i2.95

[13] A.I. Innovation Playbook I. https://www.pymnts.com/wp-content/uploads/2019/06/AI-Innovation-Playbook_Ju ne-2019.PDF

[14] A.I. Innovation Playbook II. https://www.pymnts.com/study/ai-gap-study-april-2019-study

[15] Wesli, R. (2018) Robotic Process Automation-A Study of the Impact on Customer Experience in Retail Banking Industry. Journal of Internet Banking and Commerce, 90. 